\title{
Energy Accumulation by Hydrogen Technologies
}

\author{
Jiřina Čermáková ${ }^{1,2}$, Aleš Doucek ${ }^{1,2}$, Lukáš Polák ${ }^{1,2}$ \\ ${ }^{1}$ Nuclear Research Institute, Department of Hydrogen Technologies, Husinec - ̌̌ež 130, $25068 \check{R} e \check{z}$, Czech Republic \\ ${ }^{2}$ Institute of Chemical Technology, Department of Gas, Coke and Air Protection, \\ Technická 5, 16848 Praha, Czech Republic
}

Correspondence to: cea@ujv.cz

\begin{abstract}
Photovoltaic power plants as a renewable energy source have been receiving rapidly growing attention in the Czech Republic and in the other EU countries. This rapid development of photovoltaic sources is having a negative effect on the electricity power system control, because they depend on the weather conditions and provide a variable and unreliable supply of electric power. One way to reduce this effect is by accumulating electricity in hydrogen. The aim of this paper is to introduce hydrogen as a tool for regulating photovoltaic energy in island mode. A configuration has been designed for connecting households with the photovoltaic hybrid system, and a simulation model has been made in order to check the validity of this system. The simulation results provide energy flows and have been used for optimal sizing of real devices. An appropriate system can deliver energy in a stand-alone installation.
\end{abstract}

Keywords: hydrogen, accumulation, photovoltaic.

\section{Introduction}

The main reasons for higher utilization of renewable electricity sources are the fluctuation of crude oil prices and the limited supply of fossil resources, and also global warming, local pollution and contamination, geopolitical pressure, and the growth in power consumption. Photovoltaic (PV) power plants are one type of renewable electricity source. Photovoltaic power plants produce practically zero emissions, but the amount of electricity that is produced depends on the sunlight falling on the earth's surface. PV power plants provide a variable and unreliable supply of electric power over time, and this has a negative impact on the operation of the electric power system [1]. There are two ways to overcome the variability in the output of photovoltaic power plants. One is by transposing consumption into the time when energy is available, while the other way is accumulation. The only way to accumulate electricity is by transforming it into another type of energy, e.g. into hydrogen. Hydrogen as an energy carrier enables photovoltaic energy produced in times of excess power in the grid to be stored, and then supplied to the grid when it is required, i.e., during peak periods in the daily load curve [2]. Another possible way to use the hydrogen that is produced is as a fuel for vehicles. Hydrogen-fuelled vehicles have several advantages over vehicles equipped with petrol or diesel engines, especially ecological advantages.

\section{Solar energy storage by hydrogen}

For obvious reasons, the production of electricity from PV panels is linked to the weather conditions, and is variable in the course of a day, a month, and a year. It is also unpredictable. An example of the daily PV power profile is shown in Figure 1. This load profile does not correspond closely with the energy requirements of an average household, which are represented in Figure 2. Energy requirements are unstable, and they differ between weekdays and weekends. This discordance between energy production and energy utilization can be dealt with by hydrogen accumulation.

The configuration of the proposed PV layout and hydrogen equipment is shown in Figure 3. It consists of the following components: PV panels, an electrolyzer, a fuel cell (FC), a hydrogen storage tank, and a battery [5]. The components represent the current state-of-the-art, and their parameters are presented in Table 1. The photovoltaic power plant contains 56 polycrystalline PV panels with a total area of about $90 \mathrm{~m}^{2}$. A PEM (proton exchange membrane) electrolyte made by Hogen ${ }^{\circledR}$ Company is used as the electrolyzer. The electrolyzer is a fully integrated system that includes power supply, a hydrogen gas dryer and a heat exchanger, and it generates hydrogen $\left(0-1 \mathrm{~m}^{3} / \mathrm{hr}\right)$ at 13 bars. The hydrogen is stored in a low pressure tank. A PEM fuel cell made by 


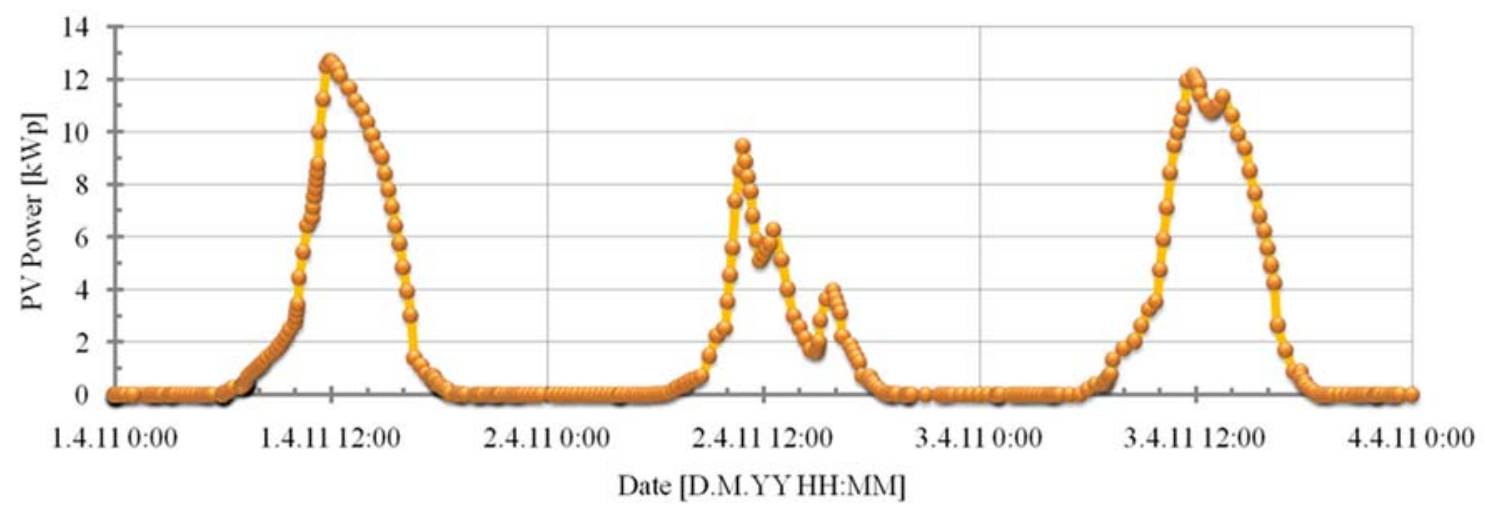

Figure 1: Load profile of electrical energy generated from PV panels, providing a power output of $12 \mathrm{kWp}$ [3]

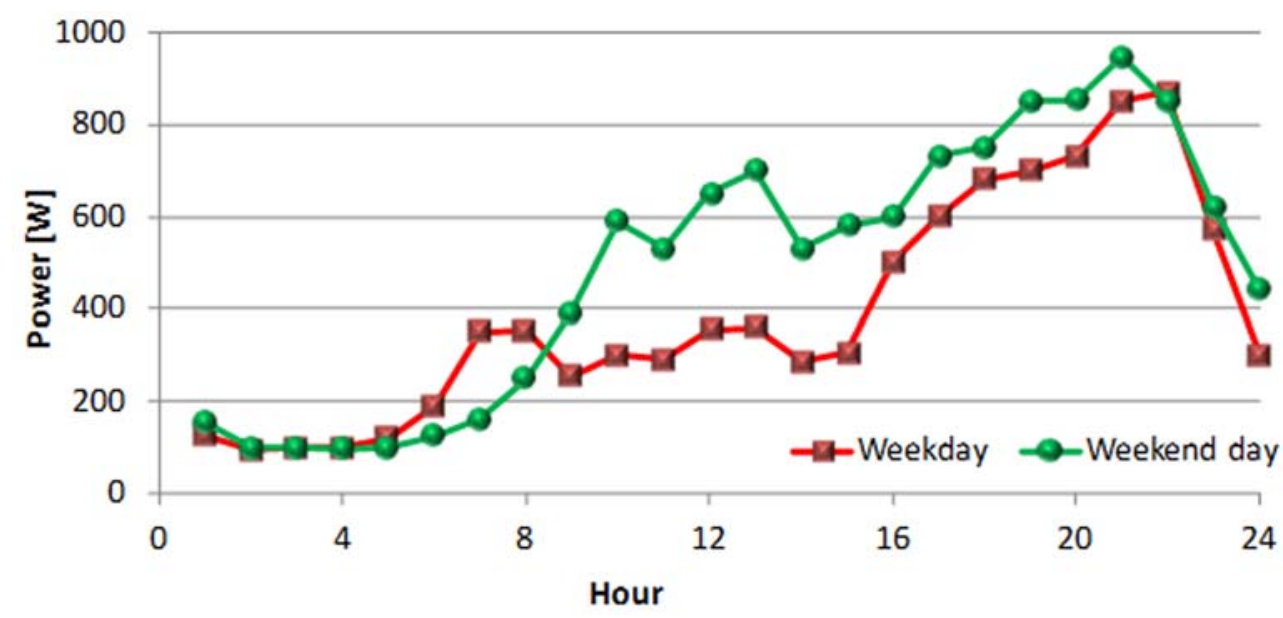

Figure 2: Average household electricity use over the day for detached houses [4]

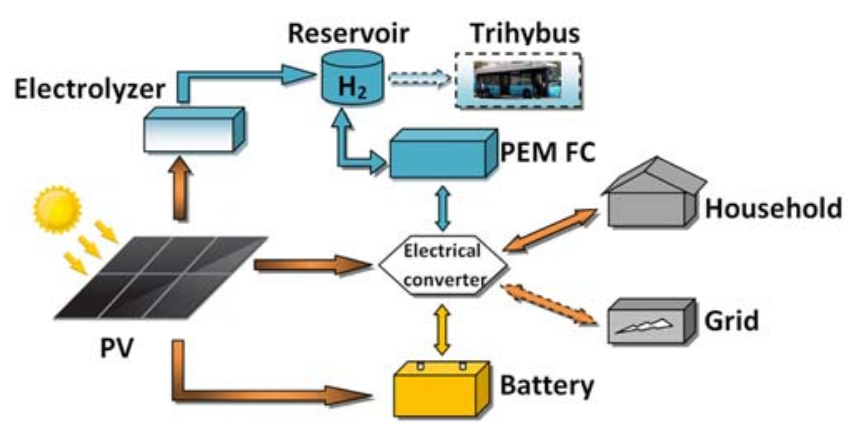

Figure 3: Configuration layout

Table 1: Parameters of the devices

\begin{tabular}{|l|l|l|}
\hline Device & Characteristic & Parameters \\
\hline Photovoltaic power plant & polycrystalline PV cell & $12 \mathrm{kWp}(230 \mathrm{~W})$ \\
\hline Battery capacity & Li-ion battery & $45 \mathrm{Ah}(2.2 \mathrm{kWh})$ \\
\hline Electrolyzer power & PEM electrolyte & $6.3 \mathrm{~kW}$ \\
\hline Fuel cell & PEM cell & $4 \mathrm{~kW}$ \\
\hline $\mathrm{H}_{2}$ storage volume & Low pressure tank & $10 \mathrm{~kg}(5-15 \mathrm{bar})$ \\
\hline
\end{tabular}


Fronius will be used as the fuel cell. A lithium-ion battery has been chosen.

The PV panels produce electrical power from the solar source. Some the power that is produced is directly consumed by the electrolyzer that produces hydrogen. Hydrogen is stored in the low pressure tank for short-term or long-term storage. The duration of storage depends on the requirements of the targeted application, and on the amount of power that is generated. The stored hydrogen is used by FC to generate electricity, or can be utilized as a fuel for cars. In our case, we will use the hydrogen for a hydrogen bus that we built and operate. The remaining part of the power that is produced is stored in a Li-ion battery, which enables a rapid response to fluctuations in renewable energy generation, as it releases power directly in response to a request from end devices.

A simulation model has been made in order to check the validity of the connection of the household with the photovoltaic hybrid system. The model, based on realistic photovoltaic production over the course of half a year (1. 4.-29. 9. 2011), and the consumption of a household, enabled the energy flow to be observed. The model is intended for a long-term evaluation of energy flow, and batteries are therefore not taken into consideration. The simulation results have been used for optimal sizing of each device, and will be verified by an experimental system.

The model was developed using Matlab/Simulink, and worked on the assumption that the photovoltaic hybrid system covers the entire energy consumption of the household, and in addition, it permits the sale of excess energy to the local electricity grid. The following input quantities are used:

- Immediate power of the photovoltaic plant [kWe]

- Immediate energy consumption of a household $[\mathrm{kWe}]$.

The output data includes

- Immediate fuel cell power $[\mathrm{kWe}]$

- Immediate hydrogen consumption $[\mathrm{kg} / \mathrm{hr}]$

- Immediate electrolyzer power [kWe]

- Immediate hydrogen production $[\mathrm{kg} / \mathrm{hr}]$.

\section{Results}

The simulation model addresses the optimum design of an integrated power system, when weather variations co-exist with varying efficiency in the performance of the electrolyzer and the fuel cell. The aim is to meet the power demands for a targeted application under a variable load schedule. The results obtained from the simulation model are shown in Figures 4 and 5. The data shows that the energy produced from the PV panels first covers the household consumption, and then the rest of energy is used by the electrolyzer, until the pressure in the hydrogen storage tank reaches a pre-specified pressure limit. When the pressure in the storage tank is below this limit, hydrogen production is initiated in the electrolyzer in order to fill the tanks. When the pressure in the tank reaches the pre-specified limit, the excess of energy is sold to the local grid. The hydrogen production is limited to the pressure limit and the maximum power of the electrolyzer $(7 \mathrm{~kW})$. The energy deficit that is generated from lack of energy from the PV panels is compensated by the use of hydrogen stored in the fuel cell, which produces electrical energy again.

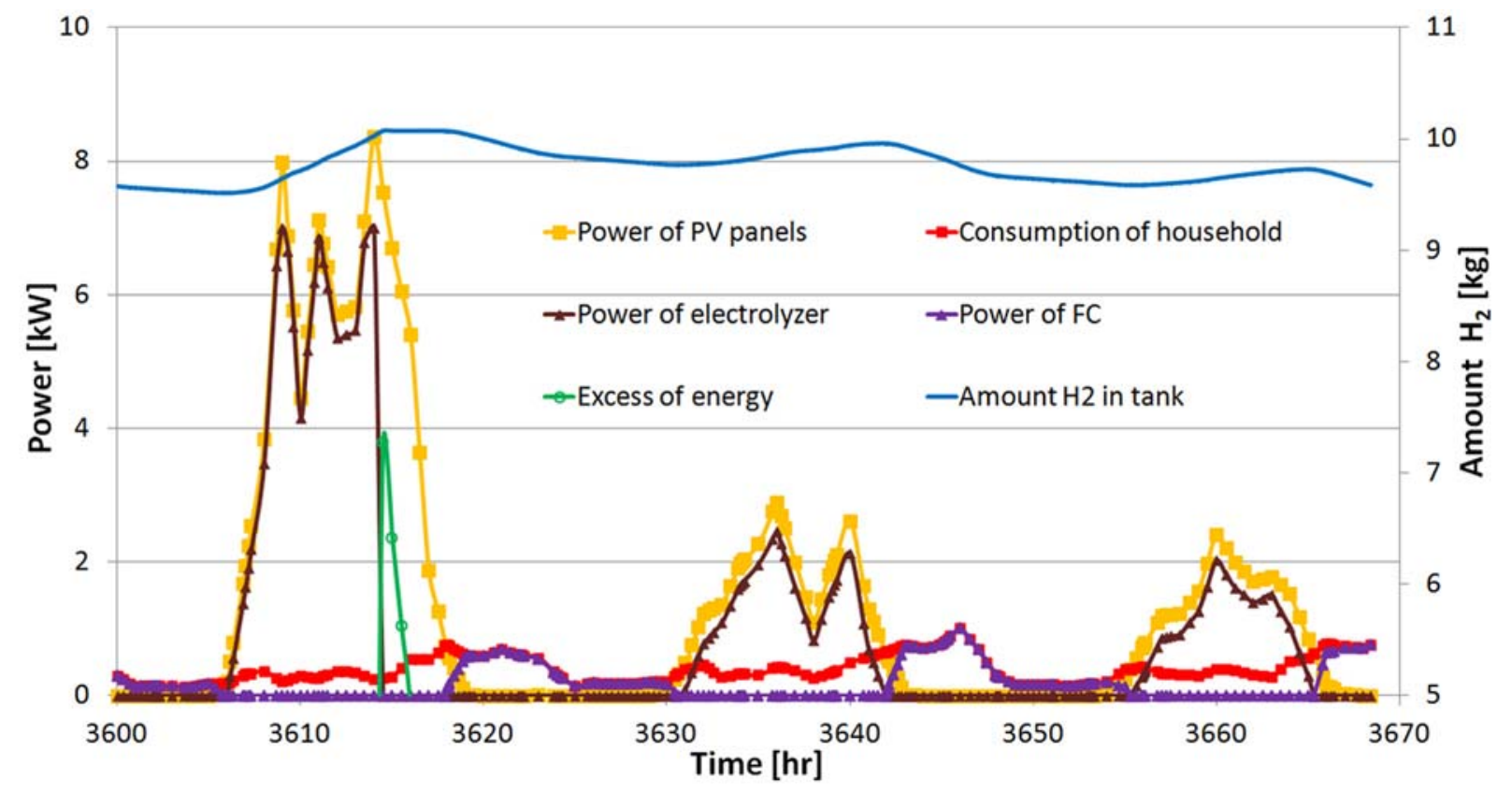

Figure 4: Results obtained from the simulation model 


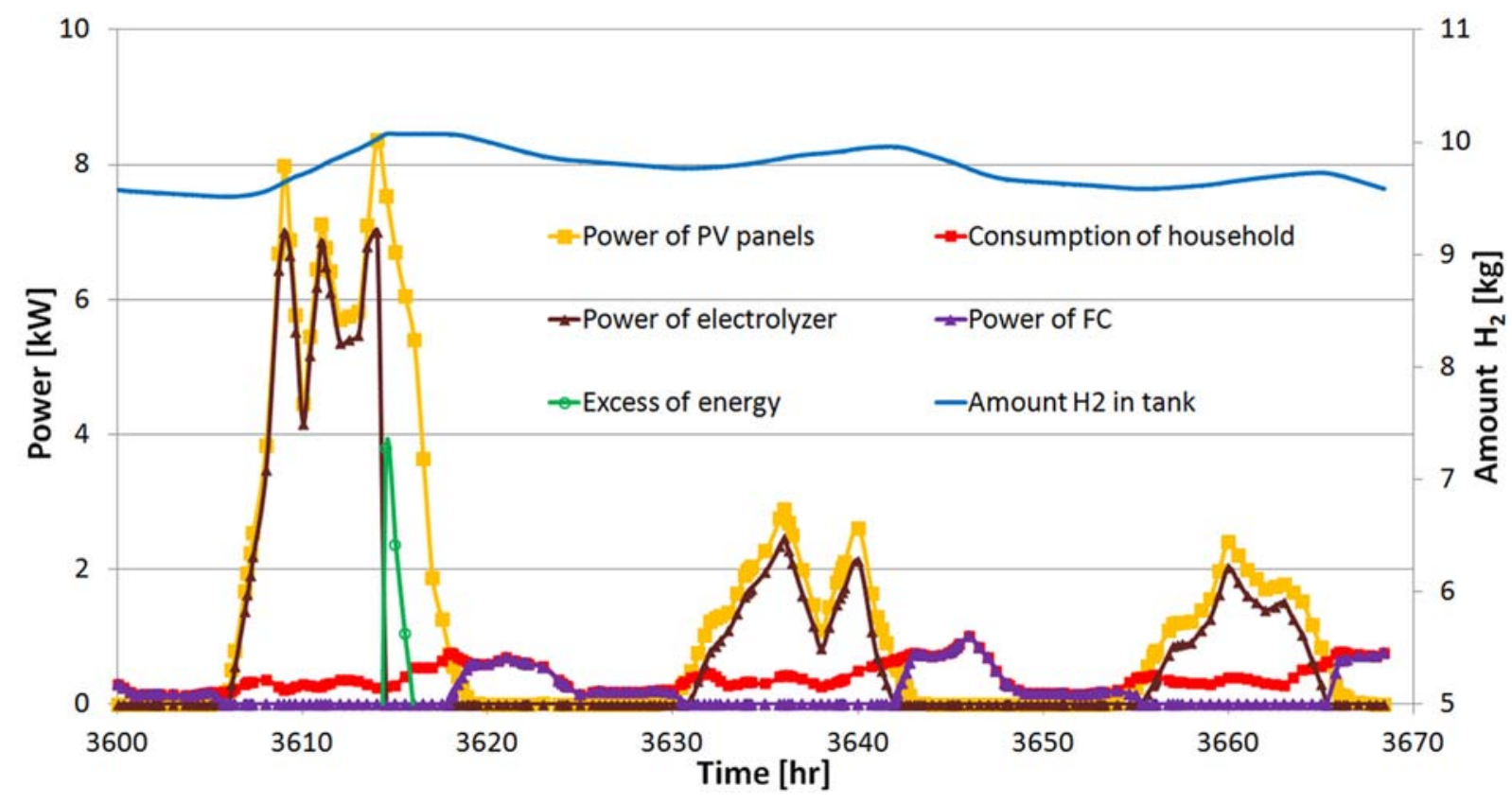

Figure 5: Results obtained from the simulation model

On the basis of an analysis of the energy flow patterns was made the following characteristic situations:

- Daily ordinary disproportion of the energy production from PV panels and the household energy consumption; basically higher energy production around midday, and lack of energy production in the evening. This disproportion is covered by using hydrogen from the storage tank. Figures 4 and 5 show that there is a requirement for about $0.3 \mathrm{~kg}$ of $\mathrm{H}_{2}$ per day.

- Longer-term lack of energy production due to unfavourable weather conditions; basically this period is not longer than 7-10 days. In this case, the required amount of stored $\mathrm{H}_{2}$ is higher, and is assessed at $2 \mathrm{~kg}$ of $\mathrm{H}_{2}$. This amount of $\mathrm{H}_{2}$ proceeds from realistic PV panel power data, which was measured in the time period from 1. 4.-29. 9. 2011. We estimate that the required amount of $\mathrm{H}_{2}$ will increase to $4 \mathrm{~kg} \mathrm{H}_{2}$ in the winter period.

Irrespective of our results, the experimental facility constructed at the Nuclear Research Institute is designed with a storage tank for $10 \mathrm{~m}^{3}$ of $\mathrm{H}_{2}$ under a working pressure of 5-15 bar. This volume is equal to approximately $10 \mathrm{~kg}$ of usable hydrogen. This relatively large volume of hydrogen allows good experimental flexibility. The parameters of the power electrolyzer and the fuel cell remain at the same level, $7 \mathrm{~kW}$ for the power electrolyzer and $4 \mathrm{~kW}$ for the fuel cell.

\section{Conclusion}

This paper has described a hybrid RES-based system, consisting of PV panels, an electrolyzer, a fuel cell and a hydrogen storage tank. In order the check the validity of this system, a simulation model was made, which is based on realistic photovoltaic production over a period of half a year. The results show two major discrepancies between energy production and energy utilization: the daily ordinary disproportion between energy is covered by $0.3 \mathrm{~kg}$ of $\mathrm{H}_{2}$, and the long-term lack of energy is covered by $2 \mathrm{~kg}$ of $\mathrm{H}_{2}$. The results indicate that this hybrid RES-based system can deliver energy in a stand-alone installation.

\section{Acknowledgement}

This work received financial support from MPO TIP FR-TI2/442.

\section{References}

[1] Giannakoudis, G., Papadopoulos, A. I., Seferlis, P., Voutetakis, S.: Optimum Design and Operation under Uncertainty of Power Systems Using Renewable Energy Sources and Hydrogen Storage. In International Journal of Hydrogen Energy, 2010, Vol. 35, p. 872-891.

[2] Moldř́k, P., Cválek, R.: Akumulace energie z fotovoltaiky do vodíku. In Elektrorevue, 2011. ISSN 1213-1539. 
[3] Doucek, A.: Návrh technického řešení pro výrobu vodiku ze solární energie. Studie č. ÚJV-FR-TI2442-2012-3, 2011, ÚJV Řež.

[4] Widén, J., Lundh, M., Vassileva, I., Dahlquist, E., Ellega, K., Wackelga, E.: Constructing Load Profiles for Household Electricity and Hot Water from Time-use Data - Modelling Approach and Validation. In Energy and Buildings, 2009, Vol. 41, p. 753-768.

[5] Lagorsea, J., Simoesm, M. G., Miraouia, A., Costergc, P.: Energy Cost Analysis of a Solarhydrogen Hybrid Energy System for Stand-alone Applications. In International Journal of Hydrogen Energy, 2008, Vol. 33, p. 2871-2879. 